\title{
Article \\ A Smart Information System for Passengers of Urban Transport Based on IoT
}

\author{
Hugo Estrada-Esquivel *, Alicia Martínez-Rebollar ${ }^{\circledR}$, Pedro Wences-Olguin, Yasmin Hernandez-Perez (D) \\ and Javier Ortiz-Hernandez
}

check for

updates

Citation: Estrada-Esquivel, $\mathrm{H}$.

Martínez-Rebollar, A.;

Wences-Olguin, P.; Hernandez-Perez, Y.; Ortiz-Hernandez, J. A Smart Information System for Passengers of Urban Transport Based on IoT.

Electronics 2022, 11, 834. https:// doi.org/10.3390/electronics11050834

Academic Editor: Prasan

Kumar Sahoo

Received: 11 December 2021

Accepted: 1 March 2022

Published: 7 March 2022

Publisher's Note: MDPI stays neutral with regard to jurisdictional claims in published maps and institutional affiliations.

Copyright: (C) 2022 by the authors. Licensee MDPI, Basel, Switzerland. This article is an open access article distributed under the terms and conditions of the Creative Commons Attribution (CC BY) license (https:/ / creativecommons.org/licenses/by/ $4.0 /)$.
TecNM/CENIDET, Computer Science Department, Cuernavaca 62490, Morelos, Mexico; alicia.mr@cenidet.tecnm.mx (A.M.-R.); d15ce096@cenidet.tecnm.mx (P.W.-O.); yasmin.hp@cenidet.tecnm.mx (Y.H.-P.); javier.oh@cenidet.tecnm.mx (J.O.-H.)

* Correspondence: hugo.ee@cenidet.tecnm.mx

\begin{abstract}
Several developed countries have implemented smart systems for public transport that provide mobility services for citizens. Most of these systems use special infrastructures to determine the location of citizens and public buses. However, the implementation of these systems does not take into account the poor infrastructure of developing countries. In Mexico, Urban Passenger Transport has insufficient transport units to meet the demand of passengers who move throughout the day, and these do not consider hardware infrastructure. Our solution is focused on inexpensive devices that are accessible to citizens, such as mobile phones. In this research work, a smart information system for passengers of urban transport is presented that allows passengers to know the expected arrival times and also to know the availability of seats on the bus that is heading towards their position. The solution was evaluated with real routes, and the results are promising for a pilot project to be put in practice.
\end{abstract}

Keywords: arrival time; urban passenger transport; passenger counter; Internet of Things

\section{Introduction}

One of the most relevant issues in cities is mobility. The current situation of traffic congestion in cities leads to several health problems derived from pollution, noise, and, obviously, the great stress in drivers who spend several hours in traffic to reach their destination [1]. Several developed cities have created smart mobility systems as new solutions to solve this problem. The implementation of systems of this kind involves the development of software and hardware infrastructure in the city. These developed countries have created passenger information systems for bus users that indicate the realtime bus location, and they have also developed several apps that provide this information directly to the smartphones of the bus users.

However, in many provinces or developing cities, there is a lack of solid human and physical infrastructure to implement intelligent transport projects. The main problem with the public transport system in Mexico is the lack of appropriate mechanisms to manage the large number of means of transportation, such as buses, metrobuses, or metro [2,3]. In the Mexican context, there are not enough public buses to cover the enormous demand for trips around the city every day. In addition, the buses are in a very bad condition. Therefore, it is very difficult to assume that buses have the needed infrastructure to publish their real-time location to their users. In Mexico, there are only a few examples of intelligent transportation systems that help users' mobility. In this scenario, intelligent mobility solutions must take into account the context of cities with limited infrastructure that have computational resources of the users that need to provide effective solutions.

Solutions are needed that use the common resources of passengers and bus drivers, such as smartphones. It is possible to take advantage of the several sensors of recent smartphones to determine location and manage remote communication with web servers. 
Moreover, cheap technological solutions are required to determine the available seats on each public bus.

This research work presents an intelligent system that improves the mobility of passengers of urban transports by allowing the users to know the arrival time of buses that are close to their current bus stop. The proposed solution also permits monitoring the availability of seats on public buses using in an electronic counter. The objective of our research is to exploit common resources of the Mexican population, such as smartphones. The solution could also be easily generalized in developing countries.

The intelligent system has been implemented on a smartphone, which obtains the GPS (Global Positioning System) position of public transport drivers and calculates the arrival time of buses that are close to the user's bus stop. The proposed system also calculates the seat availability on monitored buses using a low-cost electronic device that was developed to count the number of passengers traveling on the bus. This work presents a system for smart mobility and also the experimentation of the software system that implements the proposed approach. The experimentation demonstrates the potential usefulness of the proposed mobility system in practice in developing cities.

The paper is organized as follows: Section 2 presents the background and related work; Section 3 shows the smart information system; Section 4 shows the implementation of the smart information system; Section 5 presents the test and results obtained; Section 6 presents the scientific contributions of the research work and finally, Section 7 presents the conclusions and future work.

\section{Background and Related Work}

\subsection{Smart Cities and the Internet of Things}

A smart city is an urban development that integrates Information and Communication Technologies and the Internet of Things (IoT) technology in a secure fashion to manage a city's assets. The smart city can be defined as a city that uses information and communication technologies to improve the critical infrastructure of the city and also to make the public services for citizens more efficient [4].

A Smart City uses technology to improve the quality of life and the accessibility of its inhabitants. Additionally, it ensures sustainable economic, social, and environmental development. A smart city allows citizens to interact with it in a multidisciplinary way and also permits the city to adapt to their needs in real time [5]. The concept of a Smart City requires the implementation of mechanisms to know the real time context of the services provided to the citizens. For example, in the case of a smart mobility system, such as the one proposed in this research work, the users need to know the location of buses in real time in order to improve the times used to reach a destination.

One of the technologies that has driven the development of smart cities is the Internet of Things. There are different definitions for the concept of the Internet of Things, however, one of the most accepted definitions is the one provided by the European Research Cluster on the Internet of Things (IEC). It defined the Internet of Things as a dynamic global network infrastructure with self-configuring capabilities based on standard and interoperable communication protocols where physical and virtual "things" have identities, physical attributes, and virtual personalities, use intelligent interfaces, are seamlessly integrated into the information network, and often communicate data associated with users and their environments. This enables objects to detect their context and to communicate with others in order to interact with the context.

\subsection{Related Work}

We present a review of the related works for intelligent transportation systems for smart cities which describes the main characteristics for each work.

In the works of Gammer [6], a smart transport system was implemented using QR code (Quick Response code) technology, which is a two-dimensional barcode which is widely used for multiple purposes. This research was implemented in the city of Southampton, in 
which QR code posters were printed and placed at 44 bus stops. Each bus stop was fitted with a poster containing a unique $\mathrm{QR}$ code.

The purpose of printing the QR code posters is so that users can scan these codes with their smartphones to be redirected to a web page that will display the times of arrival of the buses. This information is taken from the Southampton traffic control center. The authors have proposed two types of posters: a simple one with minimal text, and a more comprehensive one. This was done in order to understand what level of instruction is needed for QR code use. This research work proposes a mechanism to monitor the number of hits at each stop via the website. The study revealed that there was very little variation in the use of QR codes at stops by day of the week or between peak and inter-peak times; however, there were variations by geographical area.

In the works of Yu and Lam [7], a model for predicting bus arrival times is proposed to predict bus arrival times at the same bus stop but with different routes. In this scenario, bus running times of multiple routes are used for predicting the bus arrival time of each of these bus routes. Yu and Lam have explored several techniques to predict the arrival times: a support vector machine (SVM), an artificial neural network (ANN), a k nearest neighbor algorithm (k-NN), and linear regression (LR). They found that the proposed models are more accurate than the models based on the bus running times of a single route. They also have found that a support vector machine (SVM) is the best model for predicting the bus arrival times with multiple routes.

In the research work of Li, Gao and Wei [8], an analysis of single-step and multi-step prediction models is presented as an alternative for bus arrival time prediction. In that work, three different steps are proposed to achieve the prediction of the arrival time. In the first step, the Traffic Delay Jitter Patterns (TDJP) are mined by the K nearest neighbor and $\mathrm{K}$-means in the historical traffic time data. In the second step, a short-time prediction is proposed by using a real-time adjusted Kalman filter with a modification of historical TDJP. Finally, the third step is a long-term prediction time based on a Markov historical transfer model to conduct the multi-step prediction.

As a result, Li and Gao found that the single-step prediction model performs better in accuracy and efficiency than the short-term traffic flow prediction and dynamic Kalman filter. They also found that a multi-step prediction provides a higher level of veracity and reliability in travel-time forecasting than short-term traffic flow and historical traffic pattern prediction models.

In the works of Zhou, Zheng and Li [9], a bus arrival time prediction system is presented that is based on bus passengers' participatory sensing. The proposed approach uses data provided by the mobile phones of bus passengers to collect the information of the surrounding environmental context and thus estimate the bus traveling routes and predict bus arrival time at various bus stops. The system collects the identifiers of nearby cell towers and sends that information to a server. With this solution, the authors rely on the collaborative effort of the participating users in order to be independent from the bus operating companies. A prototype was developed with several types of Android mobiles phones, that was used at a university campus and on Singapore public buses over a 7-week evaluation period. The results of the evaluation of the approach indicated a higher prediction accuracy compared to GPS solutions.

Another work is the one proposed by Wang, Zuo and Fu [10], in which the authors propose the combination of historical data and real-time situation information to predict bus arrival time. The solution proposed by Wang and Zuo is composed of two main steps. In the first step, a Radial Basis Function Neural Networks (RBFNN) model is used to learn and approximate the nonlinear relationship in historical data. In the second step, an onlineoriented method is used to adjust to the actual situation by modifying the preliminary prediction of RBFNN. The evaluation performed by the authors made on a bus route in Dalian indicates that the combination of RBFNN and online adjustment has a better prediction performance than the Multiple Linear Regression model, BP Neural Networks and RBFNN without online adjustment. 
The research work of Edison [11] presents a case study that addresses the perception of the waiting time of the passengers that use a system in real time versus those that do not use any system in real time. The authors proposed the OneBusAway transit traveler information system, which provides real-time next-bus countdown information for King County Metro users in Seattle via a website, telephone, text-messaging, and smart phone applications. The objective of that research work was to know the perception of people using the system compared to the actual time they have waited.

In the research work of Anudeep [12], an IoT system is presented to provide intelligent real-time passenger information. The system keeps the passenger updated with information about the current location of buses, estimated arrival time, and vacant seats. To provide this information, a hardware prototype was developed using NodeMCU with a GPS module, which is the tracker device that is responsible for communicating the bus location. The data coming from the electronic device is sent to the Cloud using MQTT protocol. Additionally, an Android application was developed to obtain data from the cloud and show it to the final user.

The research work of Barczak [13] analyzes how the residents of the Szczecin Metropolitan area perceive the use of telematics solutions in connection with the launch of the Szczecin Metropolitan Railway. In that case, modern infrastructure is provided by the city, for example, electronic information boards show the number of the tram or bus line, the course direction, and the waiting time for arrival. If there are no electronic boards, the passengers can use the virtual timetable by scanning the QR code that displays the arrival time of the next buses. The results of the research indicate that people living in the area near the Szczecin Metropolitan Railway have a positive opinion of the application of telematic solutions in the activities of the Szczecin Metropolitan Railway.

In the work of Baires [14], a Wireless Sensor Network for an Intelligent transportation system was developed using a Raspberry Pi. The sensing layer of the developed device has the goal of detecting if mechanical or environmental stresses during bus rides could be harmful to the device or to its performances. To do that, the device uses accelerometric, temperature, and relative humidity sensors. This information is used to alert the drivers. The proposed cost-effective WSN node was employed and tested to transmit messages and videos.

The work of Alam [15] presents a survey of Cloud-Based IoT Applications for Smart Cities considering multiple domain applications, including user mobility. The paper found several research areas in which IoT provided novel solutions. Some examples provided by the author are: vehicle circuit systems and wireless connections for smart dispatch centers, systems for fares and mobile ticketing, communication among passengers and management, vehicle monitoring, and smart parking where sensors can be used to send messages to the connected devices to find a parking space.

In the work of Sugur [16], a smart bus stop-passenger information system was developed in order to enable administrators to effectively monitor the public transportation system and also to enable the people who utilize this system to simultaneously observe the information about the location and status of those vehicles. In the proposed solution, embedded mini-computer-based systems and digital monitors were used to instantly present the information related to travel and transportation on the public transportation buses. The instant movement information of the vehicle was transferred to the central server through a GPS module that is integrated in the embedded computer systems and web services.

In the research work of Thair [17], a mobile application was proposed to help users to find public transportation and arrival times. This system provides information to determine the nearest buses to a user, the real-time location of buses on a Google map to help passengers track buses in real time, the arrival time of buses, and the speed of the buses. To do that, a specific electronic device was developed using a microcontroller with a built-in Wi-Fi module combined with a GPS sensor which is installed inside the buses. GPS is used to obtain a real-time bus location as well as speed, direction, etc. All of the data collected by ESP32 is transferred to a Blynk server through Wi-Fi, and then displayed on the mobile application. 
In the research work of Vakula [18], a system is presented where the current position of the buses and the arrival and departure times of the buses can be communicated to the passengers via the display boards in the bus terminus or via the app installed on a smartphone. The author proposed the use of a Raspberry Pi3 with a GPS and a data sensor device that needs to be installed on the bus. The device also manages the passenger count.

The research works in the literature make clear the need for solutions to improve the travel experience of bus users. The IoT and the Cloud are two technologies that are widely used in research environments to generate new solutions for mobility. One of the current trends is the development of solutions to predict the arrival times of buses. The state of the art has demonstrated the real usefulness of this trend in developed countries, where hardware infrastructure in cities enables the citizens to know the current position of public buses and, therefore, provide a prediction of the arrival time. These research works reveal several approaches that use adhoc electronic components to register the location of the bus. Citizens in these developed countries use these mobility systems normally to manage their trips in cities. However, this is not the normal scenario in developing countries without local infrastructure in buses and bus stops and where bus route schedules are chaotic. We have not found any research works in the literature to register the location of buses using the sensors of smartphones of bus drivers taking advantage of the mobile phone data network.

\section{The Proposed Smart Information System}

Today, the public transport system in Mexico does not have the functionality to provide information to determine the arrival times of buses or to know if there are available seats on the next bus that is arriving to the user's bus stop. This information is very relevant in Mexican cities where millions of users a day must be mobilized. The proposed solution is based on the fact that the current public buses do not have any kind of sensor or mechanism to determine the location of the bus.

The approach uses the resources of the bus drivers' smartphones to collect context information about public transport. This information is used by the algorithms to determine the arrival time to the next bus stop. In addition, a small electronic device was developed to record the users getting on/off of the bus. The users of public transport can use the web application developed in this project to receive the information about the arrival time of the next bus coming to the bus stop where the user is located and also to know the number of available seats on the coming bus. Figure 1 shows the conceptual architecture of the proposed system that predicts the arrival times of buses and also determines the available seats on that bus.

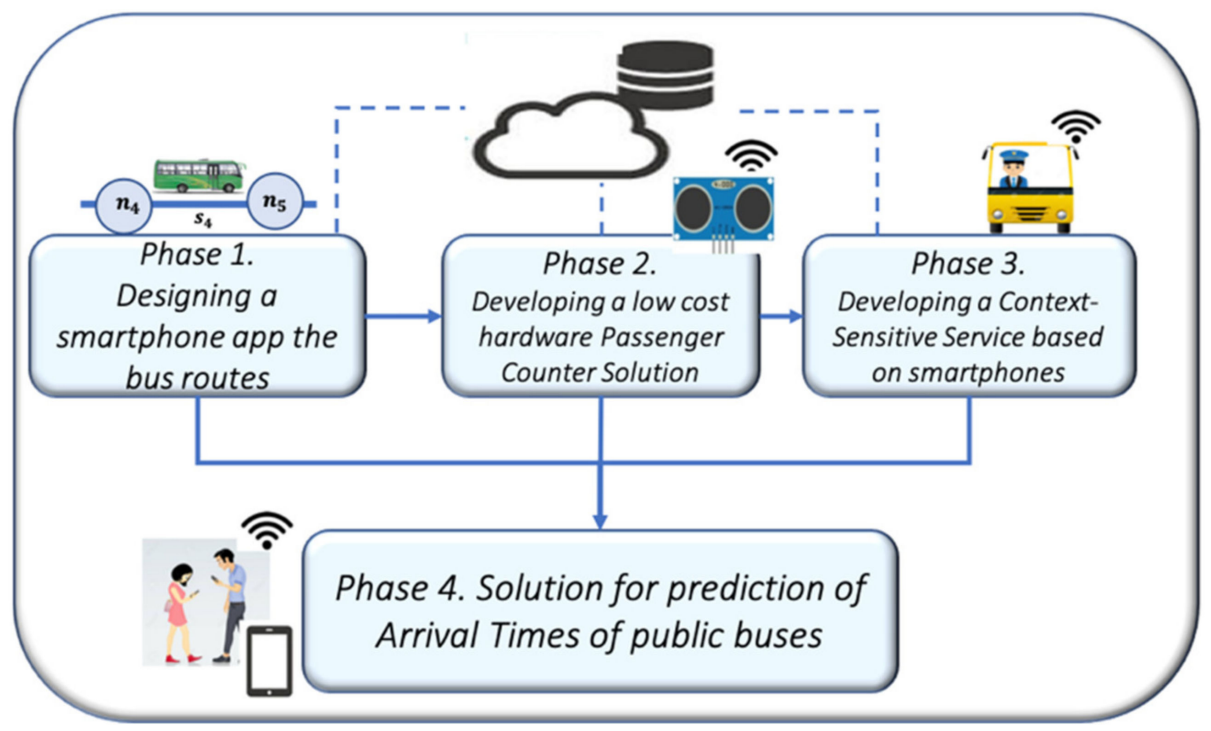

Figure 1. Overview of the proposed solution. 
The system architecture is composed of four main phases: 1 . The Route Design phase to design a specific route in the city and to indicate its corresponding bus stops. 2. The Passenger Counter Solution Development phase to propose a small device to manage the users getting on/off of the bus. 3. The Context-Sensitive Service development phase to obtain, preprocess, and send the information about Urban Passenger Transport. 4. The Prediction of Arrival Time Solution phase to provide a software solution that enables the user to visualize the predicted arrival time of buses and also the seats available on that bus. The context information produced by the bus driver's smartphones and the ultrasonic counter device is sent to the cloud using an IoT approach, where devices capture information and send it to the cloud for further analysis.

(A) Phase 1: Design of Public Bus Routes

The first phase of the proposed methodology consisted of the design of the routes of the public transport buses. The objective is to define the routes and the bus stops of the public transport agencies that need to be monitored using the proposed system. This is done using GPS location points on the route. It is important to point out that only a small number of cities in Mexico have these bus routes specified in the GTFS (General Transit Feed Specification), which indicates the routes of public transport, the bus stops, and the frequency of buses at each bus stop. In that situation, an alternative method needs to be used to indicate the route and the corresponding bus stops.

One of the aspects taken into account to design the route is that only in a few cases is an urban passenger transport route symmetrical, leaving from point A to point $B$ and returning, following the same streets in the city but in the opposite direction. This is the reason why, in this work, a route is considered to be composed of two journeys: one journey starting from bus stop A to bus stop B and another journey starting from bus stop B to return to the original bus stop A (Figure 2).

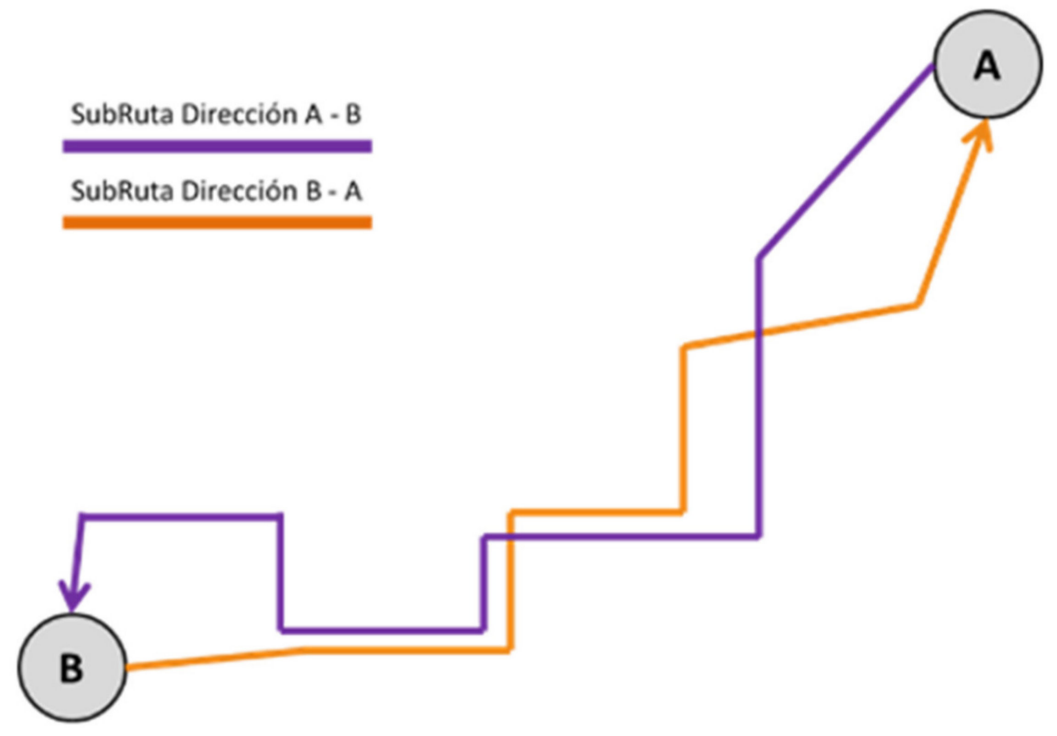

Figure 2. An example of an asymmetrical bus route.

Therefore, to design a specific route, two routes must be created with their corresponding bus stops for each route direction. The routes have been designed as directed graphs, where nodes are used to represent bus stops and edges are used to represent the distances between one bus stop and another. This module uses the API of Google maps and extends it for the definition of each bus stop for a specific route in the city. 
In the first step, the GPS position of each one of the bus stops need to be captured. This is done as follows:

- The proposed application is used to show the map of the Google Maps app on a Smartphone. The application makes use of the "Support-MapFragment" class. The geographical location where the users want to design a route is indicated on the map presented in the smartphone application. The specific method "moveCamera" is used to trace the path of the route.

- The proposed application developed for smartphones obtains the Global Position System (GPS) coordinates (latitude, longitude) where a bus stop is established on the map. This process must be completed for all of the bus stops on the route.

In the second step, a directed graph is created to represent the bus route. This is done as follows:

- The variability of the longitude and latitude of each bus stop (with the exception of the first bus stop) is analyzed and defined. Variability is defined as the increase or decrease in latitude and/or longitude with respect to the previous location.

- The bus stops are identified by assigning a position on the route and a name for the bus stop.

- The defined bus stops are drawn on the map and are also stored in a database with a unique ID.

The accuracy of the solution depends on the design of a well-defined route. In most cases, a route in the city is not completely straight and it is likely to have several curves. Therefore, care needs to be taken to define the straight and curved sections of the route. To do this, when designing the route, additional GPS points need to be assigned on the route in order to make a better match between the graphical route designed in the software app and the real bus route in the city. Figure 3 shows an example of a well-designed route and an example of a poorly-designed route.
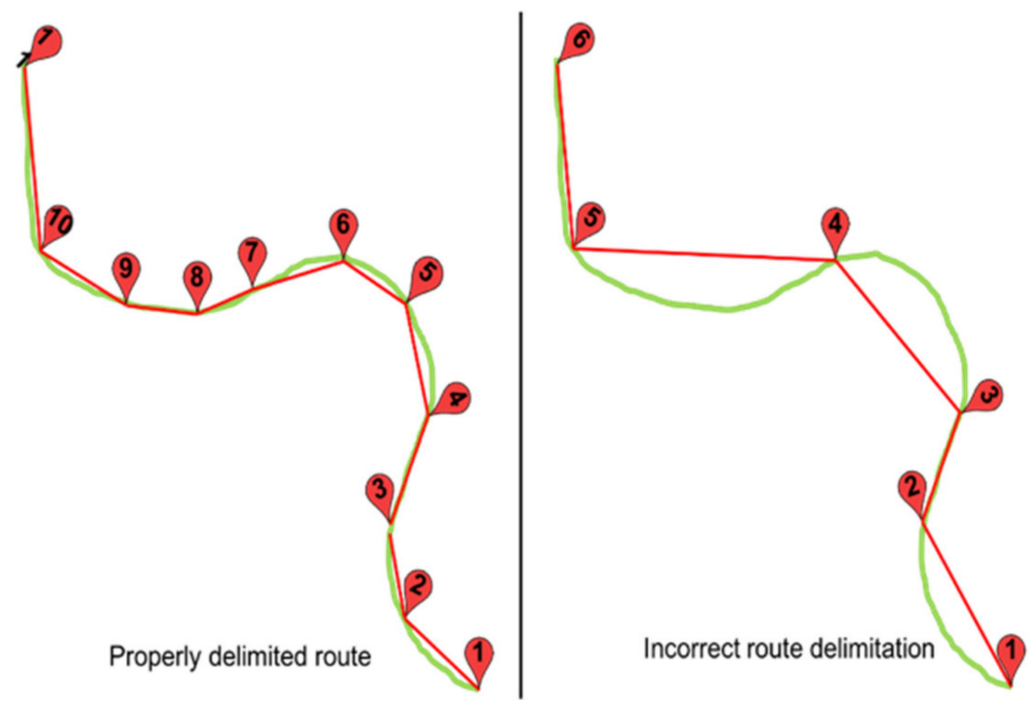

Figure 3. Example of a well-designed route and a poorly designed route.

The variability is used by the context-aware service to determine the segment where the buses are running on a route and the correct direction on the route. The GPS location of the buses is used to calculate the arrival time at the bus stops. Figure 4 shows an example of the use of variability in GPS latitude/longitude to determine the current direction of a bus on the route. 


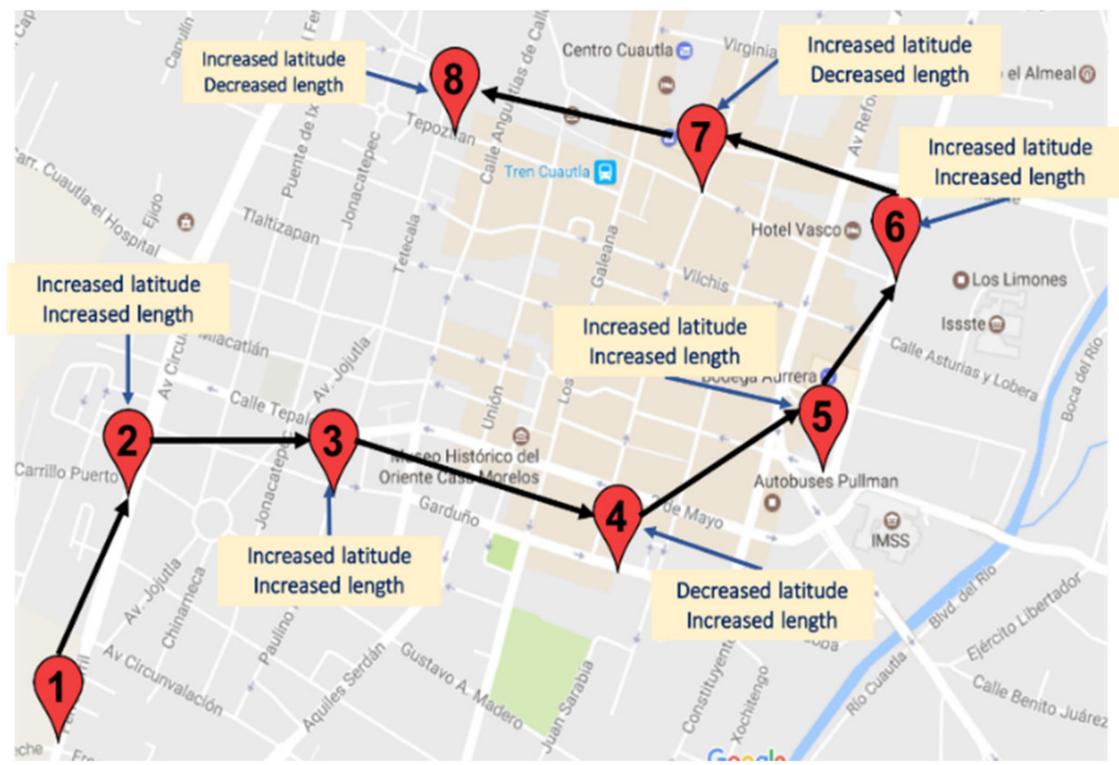

Figure 4. Example of variability of GPS.

(B) Phase 2. Passenger Counter Solution Development

In spite of the high demand for public transport services in Mexico, the users of public transport currently do not have information about seat availability on public buses, even though the service is used by a large number of users throughout the day. In order to provide a specific solution for this problem, an electronic device has been developed in this work to count the people getting on/off the buses. The device, which is called "USoniCont", allows the system to register the number of passengers getting on the bus, as well as the number of passenger getting off the bus. This information is used by the system to calculate the availability of seats on a bus.

It is important to point out that some recent buses in developed countries have devices to count passengers boarding the bus, however, these proprietary systems are used by private companies to calculate the number of people boarding the bus, and, therefore, to calculate the total amount of money that must be delivered by the bus driver. This is because today it is very rare to have buses with devices that automatically charge the cost of the travel ticket. The information generated by the counter devices does not produce real-time data and is only accessible by the companies that manage the buses. We designed the ultrasonic counter to provide information directly to the smartphone of the bus driver and then to the cloud.

The design of the ultrasonic counter was made taking into account the characteristics of commercial products on the market to register the number of people on a bus. Our passenger counter is composed of the following elements: (i) two ultrasonic sensors, which are responsible for detecting a passenger boarding or getting off of the bus; (ii) a Bluetooth module which is responsible for the communication with the smartphone of the bus driver; (iii) and an Arduino-based device which is responsible for processing the data coming from the ultrasonic device. It is also responsible for sending the "getting on/off" events to the smartphone of the bus driver through Bluetooth. The ultrasonic sensors were aligned side by side with a separation of $15 \mathrm{~cm}$. The sensors were configured to measure a maximum distance of $80 \mathrm{~cm}$, which is equivalent to the width of the door of the bus. All of the information captured from the sensors is processed using an Arduino device. Figure 5 presents the circuit diagram of the ultrasonic counter device. 


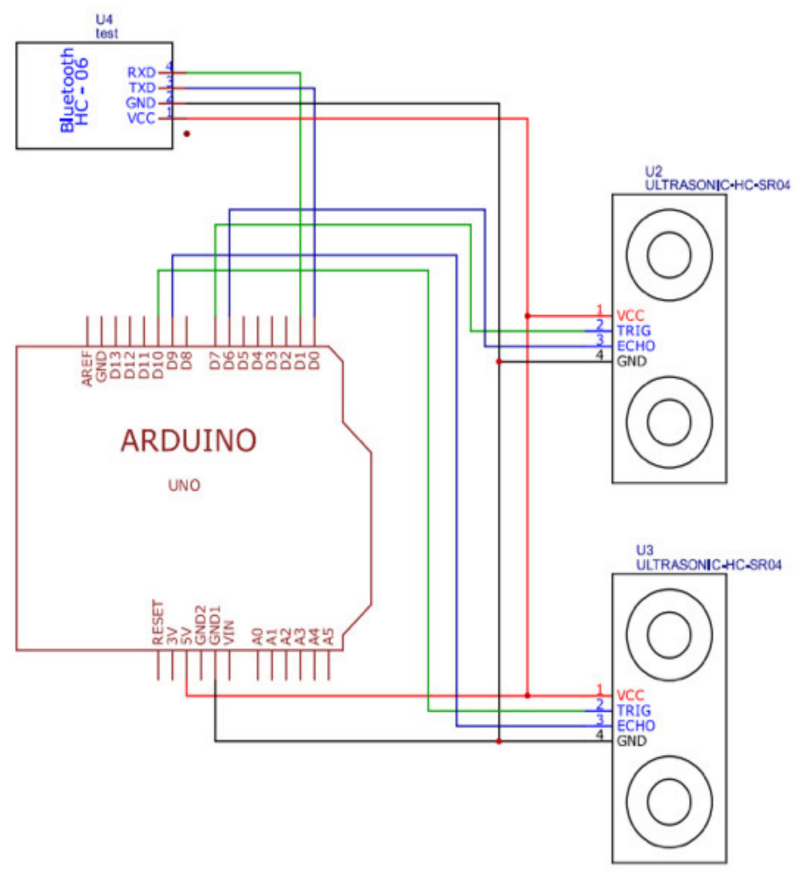

Figure 5. Circuit diagram of the ultrasonic counter device.

The USoniCont device follows the following process detailed to register when a person boards a bus (Figure 6): if a passenger walks near Sensor 1, a waiting circle is created where a counter is waiting for that user to walk near Sensor 2.

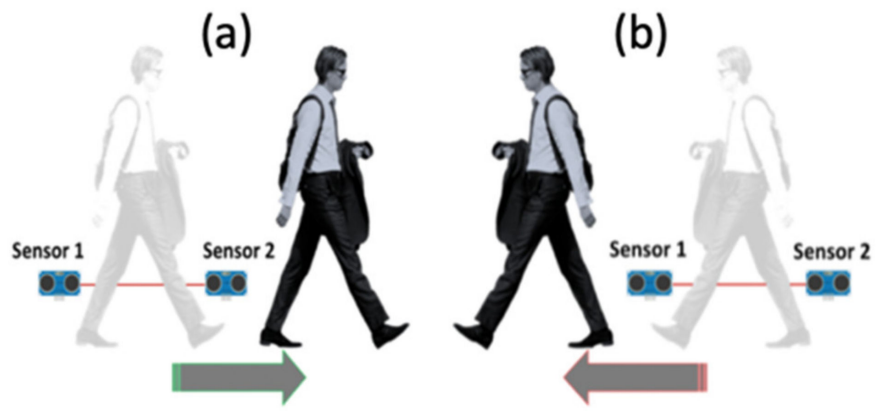

Figure 6. (a) The ultrasonic device detecting a "getting on" event; (b) the ultrasonic device detecting a "getting off" event.

When a passenger crosses near Sensor 2 before a previously defined time, the counter will record that action as a "getting on" event. If Sensor 2 does not detect the passenger, then the counter will keep the same value. Figure 6a shows the "getting on" event of a passenger.

The process is similar when a person is getting off the bus. In that case, the passenger will walk near Sensor 2 and then near Sensor 1. Figure 6b shows the "getting off" event of a passenger.

(C) Phase 3. Development of a Context-Sensitive Service

One of the relevant concepts in the design of intelligent systems is context awareness [19]. The ability of a system to know the surrounding context enables the system to react and to interact with this context. Thus, a smart software system is able to know the context in which it is being executed and then use this context information to take automated decisions and also react to changes in this environment. This means turning a system into context-sensitive services.

The context-awareness concept is also very relevant in ubiquitous computing systems and environmental intelligence [20-22]. Context awareness is a key concept in the new 
approaches of the Internet of Things where common live objects need to take the context into account in order to communicate with other objects without human intervention.

In the third phase of our proposed methodology, a context-sensitive service has been developed that obtains the context information, preprocesses this information, and finally sends the information of the Urban Passenger Transport to the cloud to be later used by the algorithms for arrival times. These software services need to be installed on the smartphone of the bus driver. The context-sensitive service integrates five functionalities: (a) obtain the data from the ultrasonic counter using the Bluetooth interface, (b) process the data coming from the passenger counter, (c) obtain the context information, (d) send the context information to the cloud, and (e) calculate the current/previous edge in which the bus is currently circulating. These functionalities are explained in detail below:

(a) Obtaining the data from the ultrasonic counter using the Bluetooth interface. This functionality enables an interface to permit the communication of the bus driver's smartphone with the UsoniCont passenger counter in order to obtain the information of passengers getting on/off. This communication is performed using the Bluetooth protocol. The proposed interface constantly reads the data produced by the ultrasonic counter and encodes this data to represent the "getting on/off" events.

(b) Processing the data coming from the passenger counter. This functionality enables an interface to modify the data of the passenger counter according to the "getting on/off" events, and it also modifies the availability of the bus seats. The available seat counter is initialized in each new trip and is modified with the "getting on/off" events. The number of available seats defines the status of the availability using three different values: good, medium, and low availability.

(c) Obtaining context information. This functionality obtains the context information when a change in the GPS position is detected. The context information is the following: the GPS position of the monitoring bus, the hour and date when data were sent, the ID of the monitored bus, the ID of the bus driver, etc. This context information is obtained from the smartphone of the bus driver as well as from the ultrasonic circuit counting passengers. Figure 7 shows the context information that is produced by a change in the location of the bus.

(d) Sending the context information to the cloud. The data that is periodically collected from the location sensor of the driver smartphone is used to determine the current/previous bus location. The context information that is produced by the smartphone of the driver and by the passenger counter needs to be sent to a Web Server. To do this, a web service has been created that is responsible for periodically sending the context information to a Web server using the JSON format. The original data obtained from sensors are transformed to a JSON object. This JSON object is continuously sent over the Internet (using the Smartphone resources) to the server. The context data are sent every $20 \mathrm{~s}$. The experimentation demonstrates that a shorter time can generate duplicated data (e.g., the GPS position) and a longer time can result in a lack of data of the bus position, making it difficult to estimate the arrival time.

(e) Calculating the current/previous edge on which the bus is circulating. This is the final functionality that is used by bus users to know the current position of the next bus and the available seating in that bus. The functionalities of this service are the following: (a) it detects on which edge of the graph representing the route the bus is located; (b) it detects the time when a bus ends and starts on each edge; and finally, (c) it detects the direction in which the bus is circulating. 


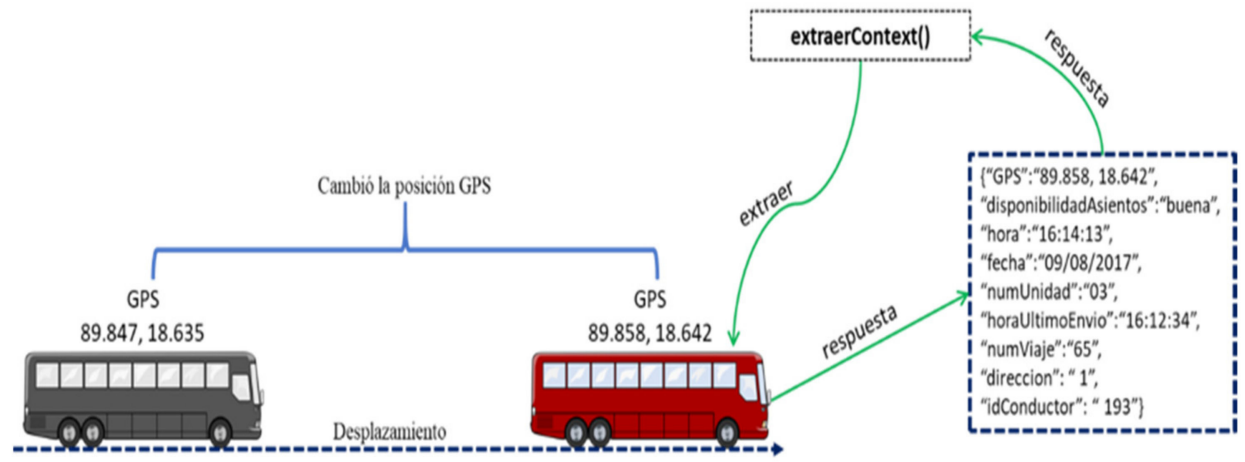

Figure 7. Context data produced by a bus on the route.

The processes for detecting the edge on which the bus is located and the previous edge are presented in detail below:

- An edge is composed of two nodes, which represent two consecutive bus stops on the route with specific GPS positions on the map. Each time the service receives the context data, it determines the edge on which the bus is located. To do this, the service validates if the GPS position of the bus is located between the interval (NodeStart-NodoEnd) of the edges of a route.

- This service detects the previous edge where a bus is circulating. In other works, when the edge on which the bus is circulating is detected, the service validates if it is the first time that the service receives data from the same edge from the same bus, which means that the bus recently entered a new edge and, therefore, ended the previous edge.

When the service detects that an edge has been traversed, the system calls the algorithm of prediction of arrival times to calculate the time used by the bus to travel the previous edge from the start node to the end node.

The direction in which a bus is circulating is obtained from the order in which the bus stops are detected by the system. For example, if the bus is at Node 3 and later the bus is at Node 4, this means that the bus direction is from point A to point B. Otherwise, the direction of the bus will be from point $B$ to point $A$. The service of the Urban Passenger Transport takes into account the detection of the GPS positions outside of the established route of each bus. In that situation, the system sends an alert to the bus agency.

Figure 8 shows the situation when a bus finishes traversing Edge E3 using the time tE3. At the instant in which the bus crosses Node 4 (N4), the context-sensitive service calculates the time spent by the bus in traversing Edge E3.

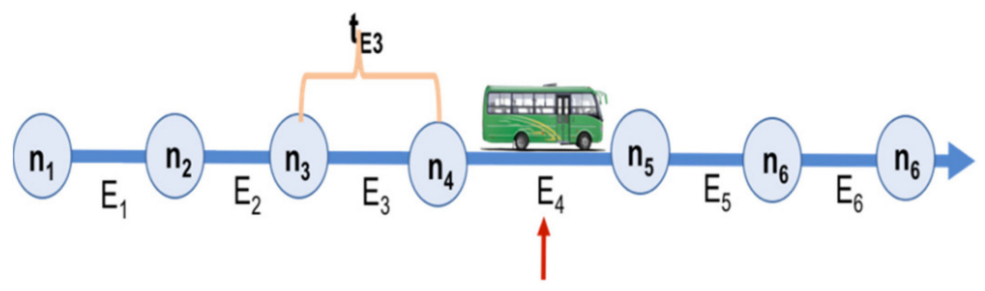

Figure 8. Time to travel an edge.

(D) Phase 4. Prediction of Arrival Time Solutions

The main purpose of this approach is to provide information to bus users about the estimated time needed for the bus to reach the bus stop where the user is located. Therefore, the main objective of the fourth phase was the development of an algorithm to calculate the arrival times of Urban Passenger Transport.

The proposed algorithm for the prediction of the arrival time is detailed in two main parts. The first part of the algorithm refers to the processing of context information captured by the context-sensitive services, while the second part of the algorithm is related to the 
process executed when the algorithm processes user queries to know the arrival of the next bus.

The first part of algorithm for processing context information is carried out as follows:

- The context-sensitive service calls for the execution of the algorithm by sending two parameters: the current edge where the bus is circulating and the edge to be calculated.

- The system database is updated with the edge on which the bus is circulating and the direction of the route.

- The algorithm verifies the edge to calculate E3 (Called Ec). Figure 9a shows the Edge E3 that must be calculated once the bus completes the entire edge.

- The travel time of the Ec edge (tEc) is calculated by searching the database for the time the bus passed through the initial and final nodes (NodeStart-NodoEnd). The experimentation demonstrated that the GPS position of the bus stops could vary with respect to the GPS position of the bus. This is because the bus location is not exactly on the GPS position of the bus stops or because the context data was not sent at the exact moment when the bus passed by the bus stop. For this reason, the algorithm searches the database for $50 \mathrm{~m}$ around the stops (see Figure $9 \mathrm{~b}$ ).

- The calculation of the time of travel of the bus by an edge is the result of a subtraction. The formula used is shown in (1).

$$
\mathrm{tEc}=\mathrm{tne}-\mathrm{tns}
$$

- The value obtained $(\mathrm{tEc})$ is averaged with the value of the database (tEdb). The greater weight should be given to the new value (because it presents the current traffic conditions) and lower weight should be given to the value stored in the database. The value of $\mathrm{tEdb}$ is calculated using Formula (2). The values 0.6 and 0.4 that modify the formula are used depending on the current of traffic conditions which increase or decrease the arrival time.

$$
\mathrm{tEdb}=(\mathrm{tEc} \times 0.6)+(\mathrm{tEdb} \times 0.4)
$$

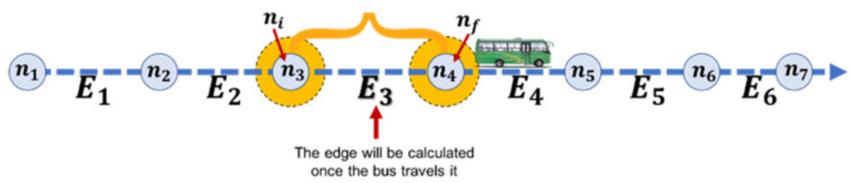

(a)

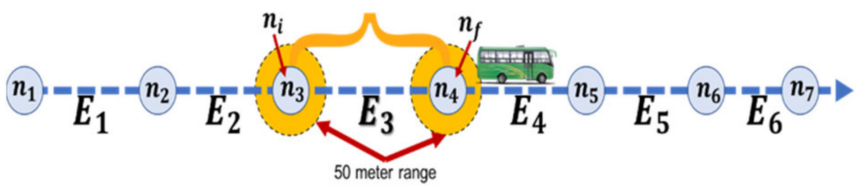

(b)

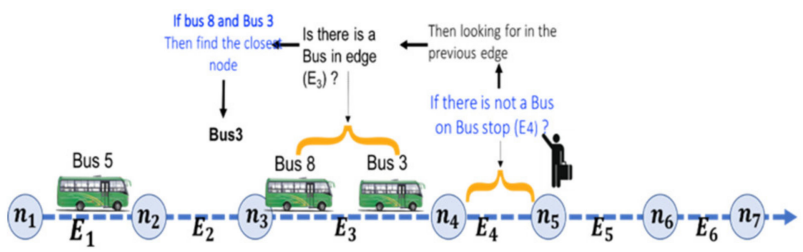

(c)

Figure 9. (a) Time of the bus to travel an edge; (b) time at which the bus passed the start node and the end node; (c) search for the closest bus. 
The second part of algorithm, to process the request made by users, is carried out as follows:

- The user uses the system interface to define a route, the direction, and a stop of the route. The proposed algorithm is the executed to respond to this user request.

- The system obtains the information of the buses that are close to the user GPS location. To do this, the proposed algorithm performs a query for the bus that is circulating on the edge before the point where the user is located. If a bus is not found on that edge, the algorithm searches the edges after the query node looking for the next bus in the same route and in the same direction. Figure 9c shows this situation.

- $\quad$ Once the system obtains the next bus arriving to the user's location, then the edges that separate the bus from the query node are also obtained by the system in order to calculate the sum of the times of the edges previous to the user's location.

- Figure 10 shows an example of the calculation of the arrival time of a bus located between Edge $n 5$ an Edge n6 to reach the position of a user located at a bus stop located at Edge $n 10$. The sum of all of the edges $t 6, t 7, t 8$, and $t 9$ is the time that the user needs to wait until the bus reaches her/his position at n10.

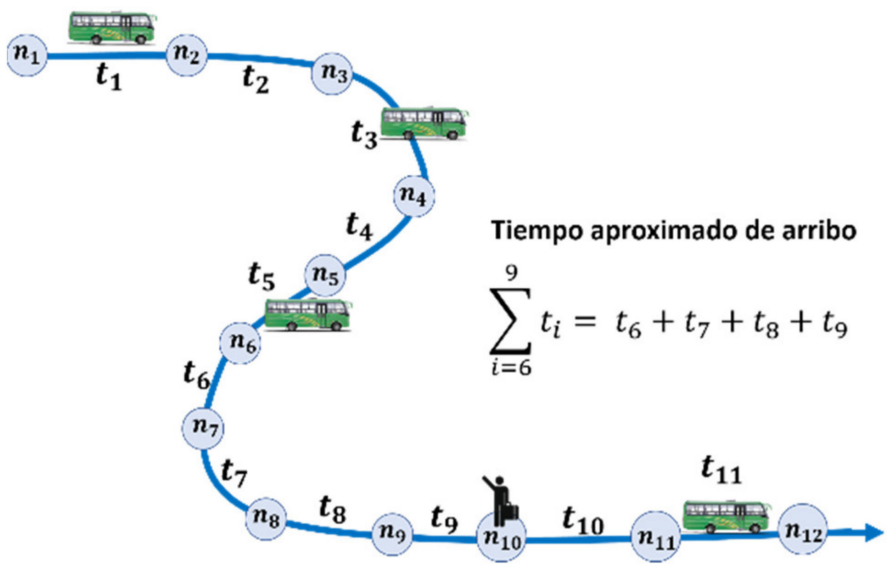

Figure 10. The calculation of the arrival time.

\section{Implementation of the Smart Information System}

This section presents a description of the architecture of the smart information system for mobility. The selected architecture is the Client-Server, where the mobile apps send their requests to the server and the server performs the processing and sends the answer to the apps. Figure 11 presents the proposed architecture of the Smart Information System. From the client-side point of view, the architecture integrates three applications that compose our solution: The Management Urban Passenger Transport App, Monitoring Drivers Context Information App, and Passenger Transport App.

The first application, called the Management Urban Passenger Transport App, enables the owners of bus agencies (concessionaires) to register their routes using the process defined in the Route Design phase. In this app, the concessionaires need to register drivers and buses and assign specific buses to a specific traffic route.

The second application, called the Monitoring Drivers Context Information App, is the app for the bus driver, which carries out the monitoring of the bus location and the monitoring of the route of the bus. This application is also responsible for sending all of the context information to the web server. 


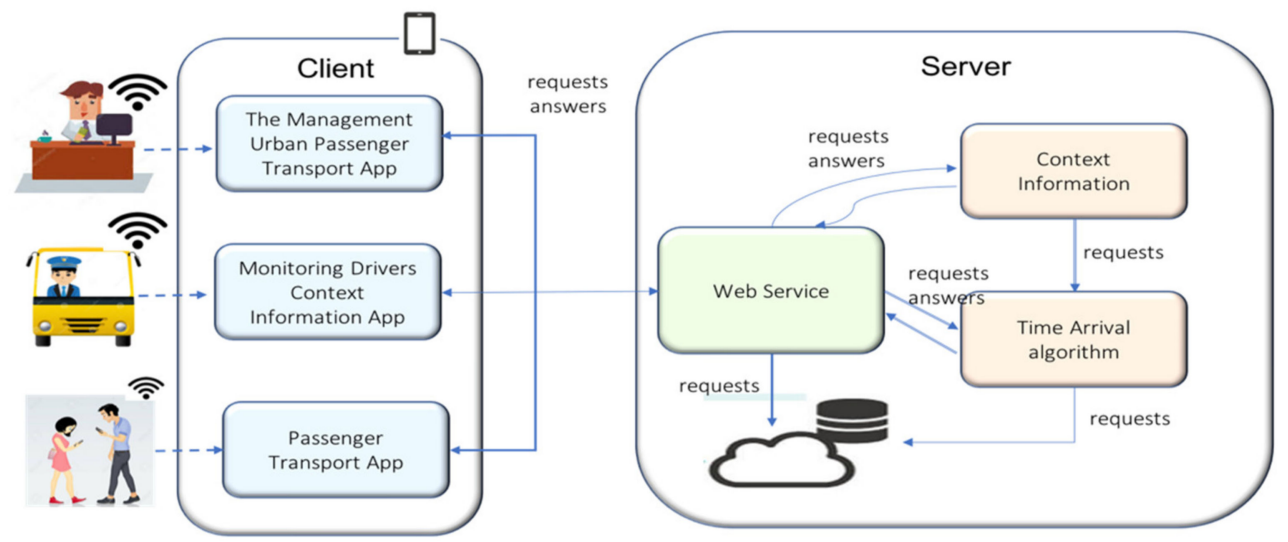

Figure 11. Architecture of the smart information system.

The third application, called the Passenger Transport App, allows passengers to check the arrival time of the next bus coming to the specific bus stop where the passenger is located at any time.

From the Server-side point of view (Figure 11), a web server was developed that manages the communication of the interface with the algorithms in order to manage the context information and the arrival time algorithm for the arrival times of buses. The process of sending requests and responses to the proposed system is carried out using Web Services technology.

It is important to point out that this proposed architecture takes into account the current situation found in most Mexican cities where there is no information about public transit routes and their schedules. Therefore, the architecture takes into account the design of the routes for local bus agencies.

The main applications that compose the proposed solution are presented below:

(a) The Management Urban Passenger Transport App

This software application was developed for the bus concessionaires to manage and to define the routes of a bus in the city and the corresponding bus stops. This app is composed of two main modules: ManageRoute and ManageDrivers.

- ManageRoutes: This module manages the information of routes, the information of the bus drivers, and the visualization of the location of the buses in real time. The users of this module are the concessionaires or the managers. The design of a new route is performed using the graphical interface of the proposed system. The first phase of the process is the creation of the new route and the definition of the route name (Figure 12).

- The second phase of the process for designing a route is to locate the geographical zone of the route. This service uses the Google map app to show the map of the route on the smartphone (Figure 13).

- The next step in the process consists of the definition of a location for each one of the bus stops. The interface permits the users to specify a point on the map, to assign the name of bus stops, and the number of this stop in the sequence of the complete route (Figure 14). This process needs to be repeated until all of the bus stops of the route are specified in the system.

- ManageDrivers: This module is responsible for registering, modifying, deleting and showing the information of the bus drivers. This module enables the concessionaires to establish the passenger capacity of the transport units. The interface of the system enables the definition of specific drivers for a route and the definition of the capacity of the public buses that compose the designed route. 


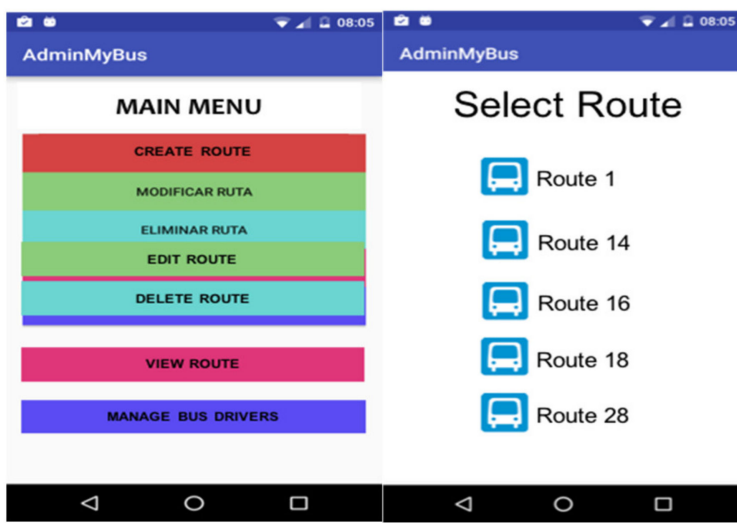

Figure 12. Interface for the creation of a new route.

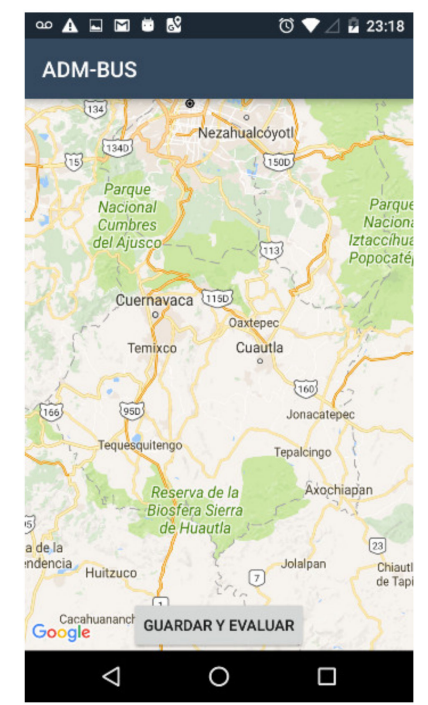

Figure 13. Graphical interface for maps.

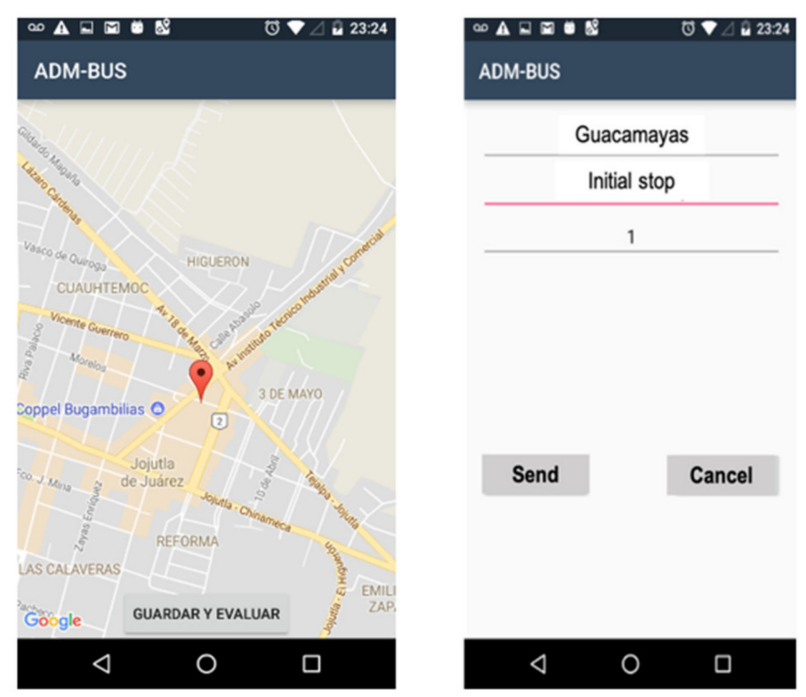

Figure 14. Interface to define the location of a bus stop. 
(b) The Monitoring Drivers Context Information App

This software application has been developed to monitor, collect, and send the context information of each bus that circulates on the route to the Web Server and to store this information in a database. To do this, the bus driver needs to be logged into the app. This module periodically communicates the following data to the Web Server: the GPS position of the bus, the seat availability, the bus unit number and the route on which the bus is circulating. Figure 15 shows the login interface for the bus driver, the interface for bus location data, and the information of the passenger counter.

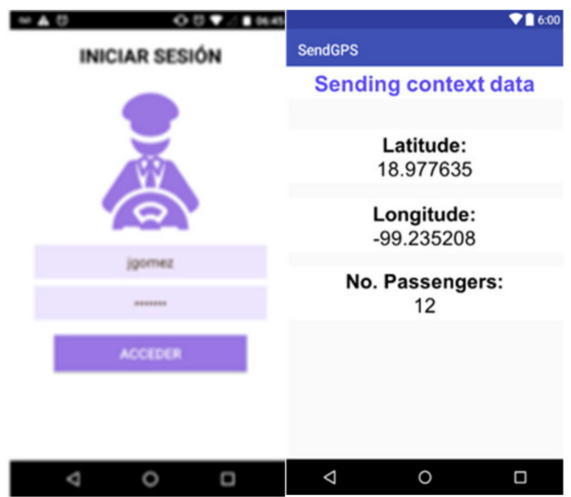

Figure 15. The login Interface for the bus driver and the interface for bus location and passengers.

Once the bus driver is logged into the system, the application enables the bus driver to know the distance between the next bus and previous bus on the route. Figure 16 shows the interface, indicating the distance (in time) to the next bus.

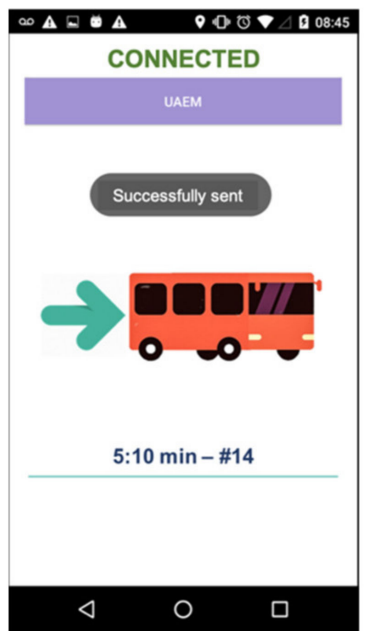

Figure 16. Interface for the bus driver.

\section{(c) Passenger Transport App}

This software application was developed for the passengers of Urban Transport to visualize the arrival time of a bus to a specific bus stop where the user is located at any time. This application needs to be installed on the smartphone of the bus passenger.

This module integrates a user interface on the smartphone to specify the bus line and direction that needs to be consulted as well as to specify the route and the specific bus stop where the user is waiting for the bus. The information provided by the app to the users allows them to make decisions about getting on the next bus or waiting for the following bus if the current one does not have available seats. Figure 17 shows some views of the interface of this module. In this example, the system displays the route name, the direction 
of the route, the specific bus stop where the user is located, the predicted arrival time, and the status of the available seats on the bus.

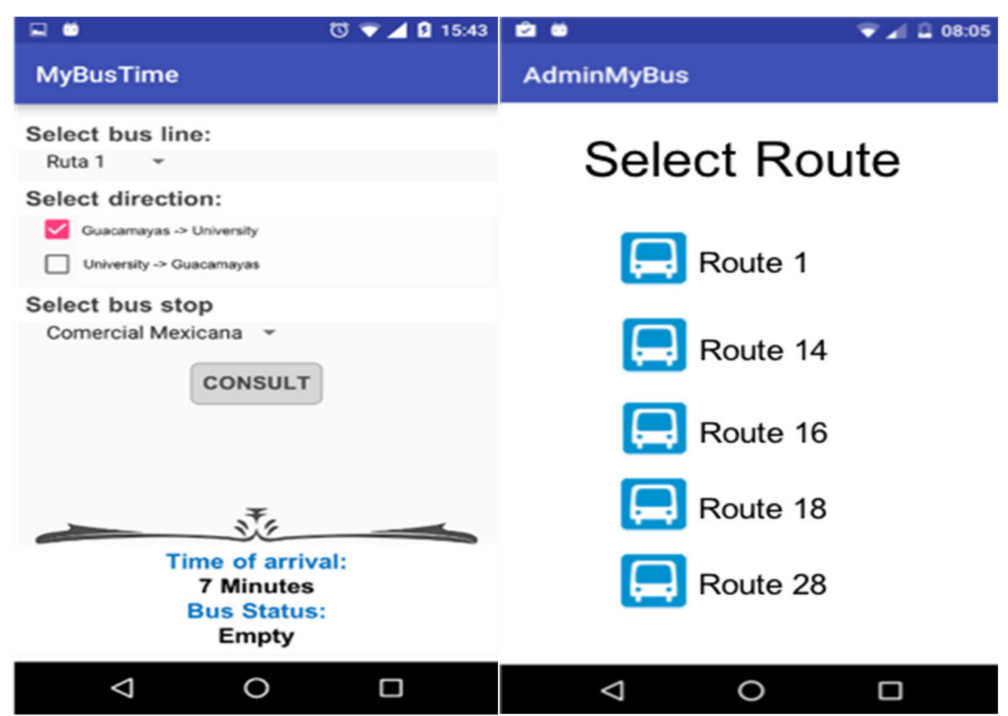

Figure 17. Some views of the interface of the Passenger Transport App.

\section{Tests and Results}

This section presents the tests and results of our proposed approach. A realistic scenario was selected to perform the experimentation of the mobility system on a bus route of a city in Mexico, specifically in the city of Cuernavaca, which is in the central region of the country. This city is a good example of most of the common cities in Mexico, where there are no schedules for public services and, therefore, the arrival times are completely chaotic. The experimentation considers a real route that crosses the city from south to north.

The first phase for the experimentation was the design of the route (which is called Route 1) with 66 bus stops: 28 bus stops on the Guacamayas-University journey and 38 bus stops in the opposite direction (University-Guacamayas journey). Figure 18 shows both directions of Route 1 . The two directions of the route are not symmetrical because some of the streets on the route are one-way streets. It is important to point out that the route needs to be designed with a software application because there are no GTFS specifications for most small Mexican cities. The GTFS specification is only available for big cities, such as Mexico City or Guadalajara.
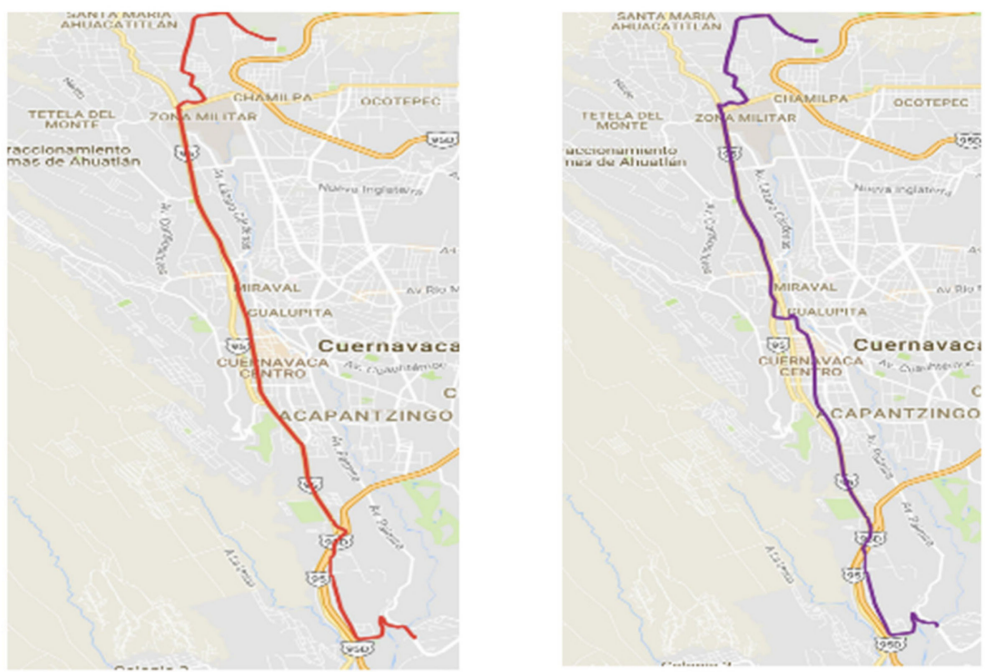

Figure 18. Design of the route used for experimentation. 
Eight trips were monitored on this bus route for experimentation; four trips for the Guacamayas-University journey and four trips for the University-Guacamayas journey.

One relevant point in testing was having very similar traffic conditions in each journey in order to reduce the error rate in arrival time predictions. To do this, the test for the journeys in the Guacamayas-University direction were done starting at 18:00 h. and the journey for the University-Guacamayas direction were done starting at 19:00 h.

As mentioned above, the Guacamayas-University direction is composed of 28 bus stops. Ten of these bus stops were selected in that direction and another 10 bus stops were selected in the opposite route (University-Guacamayas) to be monitored in the tests. The arrival times were determined using the Passenger Transport app and were compared with the real time of the arrival of the bus to the bus stop. Both the predictions and the real times were registered in a database for further evaluation.

In the evaluation, the proposed system was used to obtain the expected arrival time of the next bus. The time when the system is consulted and the time when the bus arrives to the bus stop are registered. The (Actual arrival time) Real-Time Arrival is the difference (in seconds) between the time when the software system gives the prediction and the time when the bus is currently arriving to bus stop. The Predicted Time (Predicted arrival time) represents the waiting time predicted by the proposed system.

The results obtained for experimentation are presented in Tables 1-8. Each table represents one of the eight trips: 4 trips for the Guacamayas-University journey and 4 trips for the University-Guacamayas journey. The first column indicates the number of stops being monitored. The second column indicates the Actual Arrival Time which, as commented above, represents the difference (in seconds) between the time when the software system gives the prediction and the time when the bus is currently arriving at bus stop. For example, in the first row, the time when the system was consulted to predict the arrival time was 18:18:54 h, and the time when the bus actually arrived to the bus stop was 18:20:14 h. Therefore, the difference between the two times is $80 \mathrm{~s}$. In order to simplify the visualization, only the difference in seconds is represented in the table. The third column indicates the Predicted Arrival Time, which represents the waiting time predicted by the proposed system. In the example of the first row, the time predicted (in our system) for the arrival time was $79 \mathrm{~s}$. The fourth column indicates the difference between the Actual Arrival Time and the Predicted Arrival Time, which in the example was $1 \mathrm{~s}$. The Fifth column represents the absolute percentage error, and the sixth column represents the precision of the proposed prediction algorithm, which in the example is $98.75 \%$. The difference in seconds between the estimated and real arrival times was also registered together with the medium absolute error (MAE) absolute percentage error (MAPE), and the precision of the prediction for each stop. The average MAE, MAPE, and Precision are specified for each table, for example, for complete Trip 1, the average precision was $87.2 \%$. 
Table 1. Results obtained for Trip 1 (Guacamayas-University Journey) MAE $= \pm 34 \mathrm{~s}, \mathrm{MAPE}=12.8 \%$ Precision $=87.2 \%$

\begin{tabular}{|c|c|c|c|c|c|}
\hline No. Bus Stop & Actual Arrival Time & $\begin{array}{l}\text { Predicted } \\
\text { Arrival Time }\end{array}$ & $\begin{array}{l}\text { Difference between } \\
\text { Predicted and Actual Time }\end{array}$ & Absolute Percentage Error & $\begin{array}{l}\text { Precision of } \\
\text { the Prediction }\end{array}$ \\
\hline 4 & $80 \mathrm{~s}$ & $79 \mathrm{~s}$ & $1 \mathrm{~s}$ & $1.25 \%$ & $98.75 \%$ \\
\hline 6 & $193 \mathrm{~s}$ & $171 \mathrm{~s}$ & $22 \mathrm{~s}$ & $11.40 \%$ & $88.60 \%$ \\
\hline 7 & $129 \mathrm{~s}$ & $102 \mathrm{~s}$ & $27 \mathrm{~s}$ & $20.93 \%$ & $79.07 \%$ \\
\hline 9 & $232 \mathrm{~s}$ & $241 \mathrm{~s}$ & $-9 \mathrm{~s}$ & $3.88 \%$ & $96.12 \%$ \\
\hline 11 & $301 \mathrm{~s}$ & $274 \mathrm{~s}$ & $27 \mathrm{~s}$ & $8.97 \%$ & $91.03 \%$ \\
\hline 12 & $168 \mathrm{~s}$ & $168 \mathrm{~s}$ & $0 \mathrm{~s}$ & $0.00 \%$ & $100.00 \%$ \\
\hline 13 & $409 \mathrm{~s}$ & $270 \mathrm{~s}$ & $139 \mathrm{~s}$ & $33.99 \%$ & $66.01 \%$ \\
\hline 14 & $124 \mathrm{~s}$ & $113 \mathrm{~s}$ & $11 \mathrm{~s}$ & $8.87 \%$ & $91.13 \%$ \\
\hline 15 & $290 \mathrm{~s}$ & $194 \mathrm{~s}$ & $96 \mathrm{~s}$ & $33.10 \%$ & $66.90 \%$ \\
\hline 16 & $139 \mathrm{~s}$ & $131 \mathrm{~s}$ & $8 \mathrm{~s}$ & $5.76 \%$ & $94.24 \%$ \\
\hline
\end{tabular}

Table 2. Results obtained for Trip 2, Journey: University-Guacamayas. MAE $= \pm 95.3 \mathrm{~s}$, $\mathrm{MAPE}=21.6 \%$ Precision $=78.4 \%$.

\begin{tabular}{|c|c|c|c|c|c|}
\hline No. Bus Stop & Actual Arrival Time & $\begin{array}{l}\text { Predicted } \\
\text { Arrival Time }\end{array}$ & $\begin{array}{l}\text { Difference between } \\
\text { Predicted and Actual Time }\end{array}$ & Absolute Percentage Error & $\begin{array}{l}\text { Precision of } \\
\text { the Prediction }\end{array}$ \\
\hline 18 & $280 \mathrm{~s}$ & $219 \mathrm{~s}$ & $61 \mathrm{~s}$ & $21.79 \%$ & $78.21 \%$ \\
\hline 20 & $147 \mathrm{~s}$ & $142 \mathrm{~s}$ & $5 s$ & $3.40 \%$ & $96.60 \%$ \\
\hline 21 & $81 \mathrm{~s}$ & $89 \mathrm{~s}$ & $-8 \mathrm{~s}$ & $9.88 \%$ & $90.12 \%$ \\
\hline 24 & $693 \mathrm{~s}$ & $459 \mathrm{~s}$ & $234 \mathrm{~s}$ & $33.77 \%$ & $66.23 \%$ \\
\hline 25 & $121 \mathrm{~s}$ & $128 \mathrm{~s}$ & $-7 \mathrm{~s}$ & $5.79 \%$ & $94.21 \%$ \\
\hline 27 & $156 \mathrm{~s}$ & $214 \mathrm{~s}$ & $-58 \mathrm{~s}$ & $37.18 \%$ & $62.82 \%$ \\
\hline 30 & $695 \mathrm{~s}$ & $167 \mathrm{~s}$ & $528 \mathrm{~s}$ & $75.97 \%$ & $24.03 \%$ \\
\hline 32 & $181 \mathrm{~s}$ & $149 \mathrm{~s}$ & $32 \mathrm{~s}$ & $17.68 \%$ & $82.32 \%$ \\
\hline 35 & $245 \mathrm{~s}$ & $237 \mathrm{~s}$ & $8 \mathrm{~s}$ & $3.27 \%$ & $96.73 \%$ \\
\hline 38 & $157 \mathrm{~s}$ & $145 \mathrm{~s}$ & $12 \mathrm{~s}$ & $7.64 \%$ & $92.36 \%$ \\
\hline
\end{tabular}

Table 3. Results obtained for Trip 2, Journey: Guacamayas-University. MAE $= \pm 34 \mathrm{~s}, \mathrm{MAPE}=15.7 \%$ Precision $=84.3 \%$.

\begin{tabular}{|c|c|c|c|c|c|}
\hline No. Bus Stop & Actual Arrival Time & $\begin{array}{l}\text { Predicted } \\
\text { Arrival Time }\end{array}$ & $\begin{array}{l}\text { Difference between } \\
\text { Predicted and Actual Time }\end{array}$ & Absolute Percentage Error & $\begin{array}{l}\text { Precision of } \\
\text { the Prediction }\end{array}$ \\
\hline 4 & $146 \mathrm{~s}$ & $172 \mathrm{~s}$ & $-26 s$ & $17.81 \%$ & $82.19 \%$ \\
\hline 6 & $164 \mathrm{~s}$ & $189 \mathrm{~s}$ & $-25 \mathrm{~s}$ & $15.24 \%$ & $84.76 \%$ \\
\hline 7 & $106 \mathrm{~s}$ & $136 \mathrm{~s}$ & $-30 s$ & $28.3 \%$ & $71.7 \%$ \\
\hline 9 & $282 \mathrm{~s}$ & $240 \mathrm{~s}$ & $42 \mathrm{~s}$ & $14.89 \%$ & $85.11 \%$ \\
\hline 11 & $338 \mathrm{~s}$ & $330 \mathrm{~s}$ & $8 \mathrm{~s}$ & $2.37 \%$ & $97.63 \%$ \\
\hline 12 & $208 \mathrm{~s}$ & $161 \mathrm{~s}$ & $47 \mathrm{~s}$ & $22.6 \%$ & $77.4 \%$ \\
\hline 13 & $513 \mathrm{~s}$ & $462 \mathrm{~s}$ & $51 \mathrm{~s}$ & $9.94 \%$ & $90.06 \%$ \\
\hline 14 & $111 \mathrm{~s}$ & $103 \mathrm{~s}$ & $8 \mathrm{~s}$ & $7.21 \%$ & $92.79 \%$ \\
\hline 15 & $362 \mathrm{~s}$ & $290 \mathrm{~s}$ & $72 \mathrm{~s}$ & $19.89 \%$ & $80.11 \%$ \\
\hline 16 & $165 \mathrm{~s}$ & $134 \mathrm{~s}$ & $31 \mathrm{~s}$ & $18.79 \%$ & $81.21 \%$ \\
\hline
\end{tabular}


Table 4. Results obtained for Trip 4, Journey: University-Guacamayas. MAE $= \pm 28.7 \mathrm{~s}, \mathrm{MAPE}=$ $18.8 \%$ Precision $=81.2 \%$.

\begin{tabular}{|c|c|c|c|c|c|}
\hline No. Bus Stop & Actual Arrival Time & $\begin{array}{l}\text { Predicted } \\
\text { Arrival Time }\end{array}$ & $\begin{array}{l}\text { Difference between } \\
\text { Predicted and Actual Time }\end{array}$ & Absolute Percentage Error & $\begin{array}{l}\text { Precision of } \\
\text { the Prediction }\end{array}$ \\
\hline 18 & $237 \mathrm{~s}$ & $280 \mathrm{~s}$ & $-43 \mathrm{~s}$ & $18.14 \%$ & $81.86 \%$ \\
\hline 20 & $129 \mathrm{~s}$ & $160 \mathrm{~s}$ & $-31 \mathrm{~s}$ & $24.03 \%$ & $75.97 \%$ \\
\hline 21 & $78 \mathrm{~s}$ & $45 \mathrm{~s}$ & $33 \mathrm{~s}$ & $42.31 \%$ & $57.69 \%$ \\
\hline 24 & $656 \mathrm{~s}$ & $646 s$ & $10 \mathrm{~s}$ & $1.52 \%$ & $98.48 \%$ \\
\hline 25 & $122 \mathrm{~s}$ & $165 \mathrm{~s}$ & $-43 \mathrm{~s}$ & $35.25 \%$ & $64.75 \%$ \\
\hline 27 & $141 \mathrm{~s}$ & $196 \mathrm{~s}$ & $-55 \mathrm{~s}$ & $39.01 \%$ & $60.99 \%$ \\
\hline 30 & $460 \mathrm{~s}$ & $483 \mathrm{~s}$ & $-23 \mathrm{~s}$ & $5 \%$ & $95 \%$ \\
\hline 32 & $222 \mathrm{~s}$ & $206 s$ & $16 \mathrm{~s}$ & $7.21 \%$ & $92.79 \%$ \\
\hline 35 & $223 \mathrm{~s}$ & $250 \mathrm{~s}$ & $-27 \mathrm{~s}$ & $12.11 \%$ & $87.89 \%$ \\
\hline 38 & $153 \mathrm{~s}$ & $147 \mathrm{~s}$ & $6 s$ & $3.92 \%$ & $96.08 \%$ \\
\hline
\end{tabular}

Table 5. Results obtained for Trip 5, Journey: Guacamayas-University. MAE $= \pm 42 \mathrm{~s}, \mathrm{MAPE}=20.5 \%$ Precision $=79.5 \%$.

\begin{tabular}{|c|c|c|c|c|c|}
\hline No. Bus Stop & Actual Arrival Time & $\begin{array}{l}\text { Predicted } \\
\text { Arrival Time }\end{array}$ & $\begin{array}{l}\text { Difference between } \\
\text { Predicted and Actual Time }\end{array}$ & Absolute Percentage Error & $\begin{array}{l}\text { Precision of } \\
\text { the Prediction }\end{array}$ \\
\hline 4 & $185 \mathrm{~s}$ & $160 \mathrm{~s}$ & $25 \mathrm{~s}$ & $13.51 \%$ & $86.49 \%$ \\
\hline 6 & $160 \mathrm{~s}$ & $189 \mathrm{~s}$ & $-29 \mathrm{~s}$ & $18.13 \%$ & $81.88 \%$ \\
\hline 7 & $96 \mathrm{~s}$ & $131 \mathrm{~s}$ & $-35 s$ & $36.46 \%$ & $63.54 \%$ \\
\hline 9 & $228 \mathrm{~s}$ & $263 \mathrm{~s}$ & $-35 s$ & $15.35 \%$ & $84.65 \%$ \\
\hline 11 & $443 \mathrm{~s}$ & $375 \mathrm{~s}$ & $68 \mathrm{~s}$ & $15.35 \%$ & $84.65 \%$ \\
\hline 12 & $208 \mathrm{~s}$ & $230 \mathrm{~s}$ & $-22 \mathrm{~s}$ & $10.58 \%$ & $89.42 \%$ \\
\hline 13 & $462 \mathrm{~s}$ & $468 \mathrm{~s}$ & $-6 s$ & $1.3 \%$ & $98.7 \%$ \\
\hline 14 & $115 \mathrm{~s}$ & $109 \mathrm{~s}$ & $6 \mathrm{~s}$ & $5.22 \%$ & $94.78 \%$ \\
\hline 15 & $224 \mathrm{~s}$ & $407 \mathrm{~s}$ & $-183 \mathrm{~s}$ & $81.7 \%$ & $18.3 \%$ \\
\hline 16 & $141 \mathrm{~s}$ & $130 \mathrm{~s}$ & $11 \mathrm{~s}$ & $7.8 \%$ & $92.2 \%$ \\
\hline
\end{tabular}

Table 6. Results obtained for Trip 6, Journey: University-Guacamayas. MAE $= \pm 59.4 \mathrm{~s}$, MAPE $=28.9 \%$ Precision $=71.1 \%$.

\begin{tabular}{llllll}
\hline No. Bus Stop & Actual Arrival Time & $\begin{array}{l}\text { Predicted } \\
\text { Arrival Time }\end{array}$ & $\begin{array}{l}\text { Difference between } \\
\text { Predicted and Actual Time }\end{array}$ & Absolute Percentage Error & $\begin{array}{l}\text { Precision of } \\
\text { the Prediction }\end{array}$ \\
\hline 18 & $242 \mathrm{~s}$ & $283 \mathrm{~s}$ & $-41 \mathrm{~s}$ & $16.94 \%$ & $83.06 \%$ \\
\hline 20 & $211 \mathrm{~s}$ & $127 \mathrm{~s}$ & $84 \mathrm{~s}$ & $39.81 \%$ & $60.19 \%$ \\
\hline 21 & $130 \mathrm{~s}$ & $30 \mathrm{~s}$ & $100 \mathrm{~s}$ & $76.92 \%$ & $23.08 \%$ \\
\hline 24 & $584 \mathrm{~s}$ & $679 \mathrm{~s}$ & $-95 \mathrm{~s}$ & $16.27 \%$ & $83.73 \%$ \\
\hline 25 & $106 \mathrm{~s}$ & $172 \mathrm{~s}$ & $-66 \mathrm{~s}$ & $62.26 \%$ & $37.74 \%$ \\
\hline 27 & $149 \mathrm{~s}$ & $168 \mathrm{~s}$ & $-19 \mathrm{~s}$ & $12.75 \%$ & $87.25 \%$ \\
\hline 30 & $527 \mathrm{~s}$ & $592 \mathrm{~s}$ & $-65 \mathrm{~s}$ & $12.33 \%$ & $87.67 \%$ \\
\hline 32 & $251 \mathrm{~s}$ & $355 \mathrm{~s}$ & $-104 \mathrm{~s}$ & $51.43 \%$ & $9.57 \%$ \\
\hline 35 & $242 \mathrm{~s}$ & $255 \mathrm{~s}$ & $-13 \mathrm{~s}$ & $5.37 \%$ & $9.63 \%$ \\
\hline 38 & $156 \mathrm{~s}$ & $149 \mathrm{~s}$ & $7 \mathrm{~s}$ & & $95.51 \%$ \\
\hline
\end{tabular}


Table 7. Results obtained for Trip 7, Journey: Guacamayas-University. MAE $= \pm 57.7 \mathrm{~s}, \mathrm{MAPE}=27 \%$ Precision $=73 \%$

\begin{tabular}{|c|c|c|c|c|c|}
\hline No. Bus Stop & Actual Arrival Time & $\begin{array}{l}\text { Predicted } \\
\text { Arrival Time }\end{array}$ & $\begin{array}{l}\text { Difference between } \\
\text { Predicted and Actual Time }\end{array}$ & Absolute Percentage Error & $\begin{array}{l}\text { Precision of } \\
\text { the Prediction }\end{array}$ \\
\hline 4 & $126 \mathrm{~s}$ & $163 \mathrm{~s}$ & $-37 \mathrm{~s}$ & $29.37 \%$ & $70.63 \%$ \\
\hline 6 & $157 \mathrm{~s}$ & $194 \mathrm{~s}$ & $-37 \mathrm{~s}$ & $23.57 \%$ & $76.43 \%$ \\
\hline 7 & $92 \mathrm{~s}$ & $99 \mathrm{~s}$ & $-7 \mathrm{~s}$ & $7.61 \%$ & $92.39 \%$ \\
\hline 9 & $272 \mathrm{~s}$ & $253 \mathrm{~s}$ & $19 \mathrm{~s}$ & $6.99 \%$ & $93.01 \%$ \\
\hline 11 & $271 \mathrm{~s}$ & $524 \mathrm{~s}$ & $-253 \mathrm{~s}$ & $93.36 \%$ & $6.64 \%$ \\
\hline 12 & $243 \mathrm{~s}$ & $213 \mathrm{~s}$ & $30 \mathrm{~s}$ & $12.35 \%$ & $87.65 \%$ \\
\hline 13 & $548 \mathrm{~s}$ & $494 \mathrm{~s}$ & $54 \mathrm{~s}$ & $9.85 \%$ & $90.15 \%$ \\
\hline 14 & $86 \mathrm{~s}$ & $106 \mathrm{~s}$ & $-20 s$ & $23.26 \%$ & $76.74 \%$ \\
\hline 15 & $196 \mathrm{~s}$ & $302 \mathrm{~s}$ & $-106 \mathrm{~s}$ & $54.08 \%$ & $45.92 \%$ \\
\hline 16 & $145 \mathrm{~s}$ & $131 \mathrm{~s}$ & $14 \mathrm{~s}$ & $9.66 \%$ & $90.34 \%$ \\
\hline
\end{tabular}

Table 8. Results obtained for Trip 8, Journey: University-Guacamayas. MAE $= \pm 68.8 \mathrm{~s}$, $\mathrm{MAPE}=33.8 \%$ Precision $=66.2 \%$.

\begin{tabular}{|c|c|c|c|c|c|}
\hline No. Bus Stop & Real Time Arrival & $\begin{array}{l}\text { Predicted } \\
\text { Time Arrival }\end{array}$ & $\begin{array}{l}\text { Differences Between } \\
\text { Predicted and Real Time }\end{array}$ & Absolute Percentage Error & $\begin{array}{l}\text { Precision of } \\
\text { the Prediction }\end{array}$ \\
\hline 18 & $234 \mathrm{~s}$ & $319 \mathrm{~s}$ & $-85 \mathrm{~s}$ & $36.32 \%$ & $63.68 \%$ \\
\hline 20 & $152 \mathrm{~s}$ & $231 \mathrm{~s}$ & $-79 s$ & $51.97 \%$ & $48.03 \%$ \\
\hline 21 & $112 \mathrm{~s}$ & $112 \mathrm{~s}$ & $0 \mathrm{~s}$ & $0 \%$ & $100 \%$ \\
\hline 24 & $599 \mathrm{~s}$ & $622 \mathrm{~s}$ & $-23 s$ & $3.84 \%$ & $96.16 \%$ \\
\hline 25 & $95 \mathrm{~s}$ & $137 \mathrm{~s}$ & $-42 \mathrm{~s}$ & $44.21 \%$ & $55.79 \%$ \\
\hline 27 & $158 \mathrm{~s}$ & $181 \mathrm{~s}$ & $-23 s$ & $14.56 \%$ & $85.44 \%$ \\
\hline 30 & $245 \mathrm{~s}$ & $546 \mathrm{~s}$ & $-301 \mathrm{~s}$ & $122.86 \%$ & $-22.86 \%$ \\
\hline 32 & $206 \mathrm{~s}$ & $329 \mathrm{~s}$ & $-123 \mathrm{~s}$ & $59.71 \%$ & $40.29 \%$ \\
\hline 35 & $243 \mathrm{~s}$ & $252 \mathrm{~s}$ & $-9 \mathrm{~s}$ & $3.7 \%$ & $96.3 \%$ \\
\hline 38 & $151 \mathrm{~s}$ & $152 \mathrm{~s}$ & $-1 \mathrm{~s}$ & $0.66 \%$ & $99.34 \%$ \\
\hline
\end{tabular}

The performance of the algorithm to predict the arrival times was measured by using the Root Mean Square Error (RMSE), Mean Absolute Error (MAE), Mean Absolute Percentage Error (MAPE), and Precision. Table 9 shows the results of the eight trips analyzed in the experimentation.

Table 9. Results obtained for Journeys: University-Guacamayas, Guacamayas-University.

\begin{tabular}{llllll}
\hline Direction & Trip & RMSE & MAE & MAPE & Precision \\
\hline University & 1 & $\pm 55 \mathrm{~s}$ & $\pm 34 \mathrm{~s}$ & $12.8 \%$ & $87.2 \%$ \\
\hline Guacamayas & 2 & $\pm 184 \mathrm{~s}$ & $\pm 95 \mathrm{~s}$ & $21.6 \%$ & $78.4 \%$ \\
\hline University & 3 & $\pm 38 \mathrm{~s}$ & $\pm 34 \mathrm{~s}$ & $15.7 \%$ & $84.3 \%$ \\
\hline Guacamayas & 4 & $\pm 32 \mathrm{~s}$ & $\pm 28 \mathrm{~s}$ & $18.8 \%$ & $81.2 \%$ \\
\hline University & 5 & $\pm 65 \mathrm{~s}$ & $\pm 42 \mathrm{~s}$ & $20.5 \%$ & $79.5 \%$ \\
\hline Guacamayas & 6 & $\pm 69 \mathrm{~s}$ & $\pm 59 \mathrm{~s}$ & $28.9 \%$ & $71.1 \%$ \\
\hline University & 7 & $\pm 91 \mathrm{~s}$ & $\pm 57.7 \mathrm{~s}$ & $27 \%$ & $73 \%$ \\
\hline Guacamayas & 8 & $\pm 110 \mathrm{~s}$ & $\pm 68 \mathrm{~s}$ & $33.8 \%$ & $66.2 \%$ \\
\hline
\end{tabular}


The overall results of the eight journeys of the test were the following: RMSE $= \pm 93 \mathrm{~s}$, $\mathrm{MAE}= \pm 52 \mathrm{~s}, \mathrm{MAPE}=22.4 \%$, and Precision $=76.6 \%$.

The overall precision of the proposed approach was $76.6 \%$, which is a very promising value for the initial experimentation of the solution. Several traffic issues were detected as the possible source of the difference between the predicted times and the real times: (a) Traffic in Mexican countries can be very variable from one minute to the next. In most cases, these very bad traffic conditions modify the time needed for a bus to reach a bus stop. (b) If several segments of the streets of the analyzed route are in a very bad condition, the bus is obligated to circulate in these bad segments, and it spends more time reaching the bus stop. (c) In several cases, some cars were parked in the zones established as bus stops. This means that buses needed to wait in order to find another place to stop.

The tests were also made to measure the performance of the ultrasonic counter device. To do this, the device was installed on a public bus that made five journeys. In each one of the journeys, the passengers were manually registered, and we also obtained the value of passengers detected by the ultrasonic counter for comparison. The results of precision in "getting on/off" events are presented in Table 10.

Table 10. The results obtained of the passenger counting.

\begin{tabular}{lll}
\hline Trip & $\begin{array}{l}\text { Precision in the Counting of People } \\
\text { Getting on with USonic }\end{array}$ & $\begin{array}{l}\text { Precision in the Counting of People } \\
\text { Getting off with USonic }\end{array}$ \\
\hline 1 & $91.7 \%$ & $89.8 \%$ \\
\hline 2 & $91.2 \%$ & $87.7 \%$ \\
\hline 3 & $89.7 \%$ & $94.8 \%$ \\
\hline 4 & $97.3 \%$ & $89.1 \%$ \\
\hline 5 & $88.5 \%$ & $86.9 \%$ \\
\hline
\end{tabular}

The results of the proposed ultrasonic counter look promising for managing the availability of seats on a public bus. More experimentation in several bus agencies is needed to demonstrate the feasibility in practice.

\section{Scientific Contributions}

This section of the paper highlights the scientific contribution achieved in this research work.

(a) The location of buses and the estimation of the arrival time is completely based on sensors that can be found in any of the current smartphones. The proposed approach could be easily used in cities where there is no infrastructure to manage the real-time location of public buses.

(b) A low-cost device was developed to count the number of passengers traveling on a specific bus. The device was developed using open technologies that can easily be replicated by novice students in electronics or computer science.

(c) The evaluation of the proposed approach was performed on a real route in Mexico. It is important to point out that current conditions in Mexican routes are chaotic since there are no scheduled routes to determine the expected time that buses need to arrive to each bus stop, then the current arrival times are unpredictable.

\section{Conclusions and Future Work}

Mobility in cities is one of the factors that has allowed economic development and timely access to goods and services. However, mobility is also one of the main problems in current cities. The issues related to mobility are even worse in the cities of developing countries. Several developed cities have smart mobility systems that use software and hardware infrastructure to monitor public transport buses and to provide this information to the passengers about arrival times. However, in developing countries, it is not possible 
to create solutions for mobility that use hardware infrastructure in public transport. The solutions for this cities need to consider the resources that are currently available, mainly the use of smartphones. This is the reason why the solution presented in this research work for mobility is based on cheap devices and the sensors of smartphones.

We have presented a system that allows the passengers to obtain arrival times of public buses and that also enables the users to know the seat availability on the buses approaching their current bus stop. A solution has been developed that is composed of three main applications: Management Urban Passenger Transport App, Monitoring Drivers Context Information App, and Passenger Transport App. Since the main idea of these applications is to provide a complete solution to help users of public transport, it includes the design of the routes of the public buses and a smartphone app for the passengers. It provides a graphic interface to enable the concessionaries to design a bus route and to specify the corresponding bus stops on the trip.

The applications make use of the sensors of the smartphone of the driver to communicate the bus location. The proposed algorithms use this data to calculate the direction of the bus and to predict the arrival times, taking into account the location of the passenger and the buses moving towards the current bus stops. This is a very useful application for passengers who want to know the time they will spend waiting for the next bus.

An ultrasonic device was developed to count the number of passengers getting on/off the bus in order to inform the passengers of the available seats on the bus. Therefore, the proposed solution is able to inform the users of the estimated arrival time of the next bus and also to inform them of the number of available seats on that bus.

To test the proposed approach, a real route of a bus agency was monitored to know the differences between the estimated times of arrival calculated by the algorithms and the real arrival time when the bus reached the bus stops. The test has demonstrated that the precision of the algorithms for predicting arrival time is $80.3 \%$. This will require improvements in order to reach a higher level of precision. However, it also indicates a promising scenario for using the proposed solution in practice in a Mexican city.

The limitations of this research work are related to the lack of information for public bus routes in standard formats such as GTFS; these make it easy to create mobility applications. Currently, the bus agencies need to design the routes and their corresponding bus stops in order to use the prediction algorithm.

We are currently exploring the possibility of improving the precision of arrival time prediction, taking into account the information of all of the monitored buses in order to determine the current traffic conditions that could affect a specific zone of the city. To do that, the open data of mobility in cities is being captured and placed in a unified data space. One example of the open data considered in current research is the real-time location of metrobuses of Mexico City, which provides the location of 700 public buses in the city every $30 \mathrm{~s}$. Furthermore, in order to consider the real-time traffic conditions in cities, the data of APIs of mobility applications is currently being used. An example of this trend is the use of Here Maps API to obtain traffic data in real time for several segments of Mexican cities. Here Maps obtains information about the density of traffic in a specific city area. Another developing work in the project is the combination of the proposed approach with a planning route for cities that uses the public transport agencies that provide data using GTFS specifications.

Author Contributions: Conceptualization, A.M.-R.; methodology, H.E.-E., A.M.-R., P.W.-O., Y.H.-P. and J.O.-H.; software, P.W.-O.; investigation, H.E.-E., A.M.-R. and P.W.-O.; writing-original draft, H.E.-E., A.M.-R. and Y.H.-P.; writing - review and editing, J.O.-H. All authors have read and agreed to the published version of the manuscript.

Funding: This research received no external funding.

Informed Consent Statement: Informed consent was obtained from all subjects involved in the study.

Conflicts of Interest: The authors declare no conflict of interest. 


\section{References}

1. Allen, J.; Muñoz, J.C.; Ortuzar, J.D. Modeling service specific and global transit satisfaction under travel and user hetereogeneity. Transp. Res. Part A Policy Pract. 2018, 113, 509-528. [CrossRef]

2. INEGI. Main Characteristics of the Passenger Transport Network in Mexico City. 2020. Available online: https://cutt.ly/ggdoNne (accessed on 21 April 2021).

3. National Commission for Human Rights, CNDH. Movilidad, Vivienda y Derechos Humanos. Available online: http://appweb. cndh.org.mx/biblioteca/archivos/pdfs/cartilla-Movilidad-Vivienda-DH.pdf (accessed on 21 April 2021).

4. Avatefipour, O.; Sadry, F. Traffic Management System Using IoT Technology-A Comparative Review. IEEE Int. Conf. Electro Inf. Technol. 2018, 1041-1047. [CrossRef]

5. Yankevich, N. Systematic integrated approach to quantifying preventive diagnostics in a 'smart' transport system. J. Ind. Eng. Int. 2019, 15, 479-486. [CrossRef]

6. Gammer, N.; Cherrett, T.; Gutteridge, C. Disseminating real-time bus arrival information via QRcode tagged bus stops: A case study of user take-up and reaction in Southampton, UK. J. Transp. Geogr. 2014, 34, 254-261. [CrossRef]

7. Yu, B.; Lam, W.H.K.; Lam, M. Bus arrival time prediction at bus stop with multiple routes Transp. Transp. Res. Part C Emerg Technol. 2011, 19, 1157-1170. [CrossRef]

8. Li, J.; Gao, J.; Yang, Y.; Wei, H. Bus arrival time prediction based on mixed model. China Commun. 2015, 14, 38-47. [CrossRef]

9. Zhou, P.; Zheng, Y.; Li, M. How long to wait? Predicting bus arrival time with mobile phone based participatory sensing. In Proceedings of the 10th International Conference on Mobile Systems, Applications, and Services-MobiSys, Ambleside, UK, 25-29 June 2012; Volume 13, pp. 379-392. [CrossRef]

10. Wang, L.; Zuo, Z.; Fu, J. Bus arrival time prediction using RBF neural networks adjusted by online data. Procedia-Soc. Behav. Sci. 2014, 138, 67-75. [CrossRef]

11. Edison, K.; Ferris, B.; Borning, A.; Rutherford, G.S.; Layton, D. Where is my bus? Impact of mobile real-time information on the perceived and actual wait time of transit riders. Transp. Res. Part A Policy Pract. 2011, 45, 839-848. [CrossRef]

12. Anudeep, P.; Krishna, P. Intelligent Passenger Information System Using IoT for Smart Cities. Adv. Intell. Syst. Comput. 2018, 851, 67-76.

13. Barczak, A. The Expectations of the Residents of Szczecin in the Field of Telematics Solutions after the Launch of the Szczecin Metropolitan Railway. Information 2021, 12, 339. [CrossRef]

14. Baire, M.; Melis, A.; Lodi, M.B.; Dachena, C.; Fanti, A.; Farris, S.; Pisanu, T.; Mazzarella, G. WSN Hardware for Automotive Applications: Preliminary Results for the Case of Public Transportation. Electronics 2019, 8, 1483. [CrossRef]

15. Alam, T. Cloud-Based IoT Applications and Their Roles in Smart Cities. Smart Cities 2021, 4, 1196-1219. [CrossRef]

16. Sungur, C.; Babaoglu, I.; Sungur, A. Smart Bus Station-Passenger Information System. In Proceedings of the 2015 2nd International Conference on Information Science and Control Engineering, Shanghai, China, 24-26 April 2015; pp. 921-925. [CrossRef]

17. Salih, T.; Younis, N. Design an Intelligent Real-Time Public Transportation Monitoring System Based on IoT. Open Access Libr. J. 2021, 8, 1-14. [CrossRef]

18. Vakula, D.; Raviteja, B. Smart public transport for smart cities. In Proceedings of the 2017 International Conference on Intelligent Sustainable Systems (ICISS), Palladam, India, 7-8 December 2017; pp. 805-810. [CrossRef]

19. Emmanouilidis, C.; Koutsiamanis, R. Mobile guides: Taxonomy of architectures, context awareness, technologies and applications J. Netw. Comput. Appl. 2013, 36, 103-125. [CrossRef]

20. Perera, C.; Zaslavsky, A.; Christen, P.; Georgakopoulos, D. Context aware computing for the internet of things: A survey. IEEE Commun. Surv. Tutor. 2014, 16, 414-454. [CrossRef]

21. Cook, D.J.; Augusto, J.C.; Vikramadiya, R. Ambient intelligence: Technologies, applications, and opportunities. Pervasive Mob. Comput. 2009, 5, 277-298. [CrossRef]

22. Synott, G.; Chen, J.; Nugent, L.; Moore, C.D. Flexible and customizable visualization of data generated within intelligent environments. In Proceedings of the 2012 Annual International Conference of the IEEE Engineering in Medicine and Biology Society, San Diego, CA, USA, 12 November 2012. [CrossRef] 